\title{
Propostas alternativas de construção de políticas públicas em educação: novas esperanças de solução para velhos problemas?
}

\section{Alternative proposals for constructing public education policies: new hope for solving old problems?}

\author{
Salete Campos de Moraes*
}

\begin{abstract}
RESUMO
Discute-se a possibilidade de construção de políticas públicas alternativas no campo da educação, não apenas como proposições teóricas, mas aquelas construídas na perspectiva oposta à da tradição brasileira, qual seja, a de verticalização das relações entre Estado e sociedade civil. Ainda que se considere os recuos, obstáculos e entraves que caracterizam as mudanças de paradigmas em políticas públicas educacionais, é de se ressaltar que, nos últimos anos, tem-se construído, em várias cidades do país, novas formas de fazer política pública em educação. Tais experiências refletem projetos que trazem consigo a concepção de democratização das relações entre Estado e sociedade, e podem representar novas esperanças de solução para velhos problemas.

Palavras-chave: políticas públicas em educação; propostas alternativas em políticas educacionais; democratização das relações entre Estado e sociedade.
\end{abstract}

* Socióloga. Mestre em Sociologia pela UFRGS. Doutora em Educação pela UNISINOS. Professora da Faculdade de Educação da Pontifícia Universidade Católica do Rio Grande do Sul - Brasil. Correio eletrônico: saletecm@pucrs.br 


\begin{abstract}
This paper examines the possibility of constructing alternative public education policies, not only theoretical proposals, but also educational policies that have been constructed in opposition to the Brazilian tradition of vertical relations between the state and civil society. Even taking into account the difficulties that characterise paradigm shift in education policies, it can be seen that new approaches to such policies have been constructed in a number of brazilian cities in recent years. These experiences reflect forms of government that involve the concept of democratisation of the relations between state and society, which may represent new hope for solving old problems.
\end{abstract}

Keywords: public education policies; alternative proposals for education policies; democratisation of relations between state and society.

Neste trabalho se discute a possibilidade de construção de políticas públicas alternativas no campo da educação, uma vez que as políticas educacionais, sobretudo nas sociedades contemporâneas, são construídas em meios marcados pela heterogeneidade e pela complexidade (TEODORO, 2004). Na América Latina, é sobretudo o Banco Mundial quem conduz as políticas sociais, sendo sempre portador de um modelo verticalizado (top-down), ou seja, os programas de ajuda vêm prontos para serem aplicados, independentemente do contexto social e da especificidade histórica dos países ou regiões (TEODORO, 2005). Entretanto, em diferentes países da América Latina existem alternativas em políticas públicas que buscam contemplar, ao mesmo tempo, a ampla diversidade de realidades e incluir, em sua construção, o conjunto de atores sociais.

A perspectiva que pauta esta investigação é a sociologia das ausências e das emergências, pois, assim como Boaventura de Sousa Santos, entende-se que a experiência social em todo o mundo é muito ampla e variada e que muito dessa experiência social tem sido desperdiçada pela tradição científica ocidental. Assim, partilha-se da ideia de que precisamos " [...] procurar o que falta no presente, naquilo que existe. A negatividade do presente não é o que lhe falta, é o que no presente bloqueia aquilo que nos faz falta e a que temos direito" (SOUSA SANTOS, 2001, p. 19).

Assim, discutem-se não apenas proposições elaboradas no campo teórico acerca da possibilidade de construção de políticas educacionais com cunho participativo, mas também políticas educacionais que foram, efetivamente, construídas na perspectiva oposta a da tradição brasileira de verticalização das relações entre Estado e sociedade civil. Apresentam-se aqui algumas experiências alternativas de políticas públicas em educação que foram concebidas e 
implementadas por órgãos governamentais, no Brasil, e que continham e/ou contêm, como pressuposto, a democracia participativa.

Quando se pretende discutir possibilidades de construção de políticas públicas alternativas em educação, é quase inevitável que venha à mente a proposta das Cidades Educadoras. A expressão "cidade educativa", ou "educadora", popularizou-se extraordinariamente nos últimos anos, mas a ideia que ela envolve pode ser encontrada em pedagogias muito antigas. Assim, é praticamente obrigatória a referência à relação íntima que se estabelecia, na Grécia clássica, entre paideia e polis. Ou também, por exemplo, teriam que ser citadas as utopias renascentistas, que desenham cidades nas quais a educação desempenhava um papel fundamental. De certo modo, a ideia de cidade educadora foi também intuída pelos renovadores pedagógicos que, no século XX, pretenderam "desensimesmar" as instituições educativas e abri-las ao seu entorno, integrando-as à vida da comunidade. Entretanto, no que se refere concretamente à expressão "cidade educativa", é certo que sua difusão atual se deve em grande medida, ao famoso informe Aprender a ser, elaborado por Faure et al (apud TRILLA, 1997) no início dos anos setenta, por solicitação da UNESCO. O título da terceira parte deste informe foi: "Para uma cidade educativa", porém, apesar do título, esta parte do trabalho não faz alusão exclusiva nem específica ao meio urbano ou à cidade propriamente dita. A expressão "cidade educativa" basicamente cumpria, ali, uma função metafórica (TRILLA, 1997).

No início dos anos 90, recupera-se a força desta expressão. Ou, mais exatamente, surge a "cidade educadora". Substitui-se o termo "educativa", que sugere que a cidade é um mero fator de educação, por "educadora", que indica seu caráter de agente, ou seja, a mudança é feita para ressaltar o caráter formador que as cidades devem assumir. Essa recuperação se produz, sobretudo, a partir do Congresso Internacional de Cidades Educadoras, que aconteceu em Barcelona, em 1990, no qual foi aprovada a "Carta das Cidades Educadoras" (TRILLA, 1997).

A partir de então, ocorreram vários encontros bianuais, quando se constituiu a Associação Internacional das Cidades Educadoras (Aice). O objetivo das Cidades Educadoras é trabalhar conjuntamente, com sentido educativo, para o desenvolvimento de políticas e atuações que impulsionem a qualidade de vida das pessoas, seu compromisso com o espírito de cidadania e com os valores de uma democracia participativa e solidária (AICE, 2004).

O projeto de cidade educadora é uma bela utopia que, salvo casos excepcionais e muito localizados, não frutificou na prática (CARBONEL, 2000). Já na avaliação de Maria Belén Caballo Villar, a ideia-projeto de Cidade Educadora é um enquadramento teórico, que surge como expressão da nova sensibilidade e concepção que se vem desenvolvendo sobre as funções, os recursos e as po- 
tencialidades dos núcleos urbanos (CABALLO VILLAR, 2001).

Porém, o que importa destacar, é que "cidade educadora", mais do que uma categoria precisa, representa uma ideia-força, uma denominação extraordinariamente genérica, que abarca, simultaneamente, significados puramente descritivos, e conteúdos claramente indicadores de desejos, aspirações. É também, no melhor sentido da palavra, um lema, um chamamento. Um slogan sugestivo, que proporciona uma imagem muito adequada à complexidade do fazer educativo. O lema "cidade educadora" tem também uma função de sensibilização, tanto dos cidadãos, a respeito da dimensão educativa da cidade, quanto dos gestores municipais em relação à necessidade de fazer com que a cidade seja mais propositivamente formadora. O lema tem também muito de utopia, configurada pelo anseio de construção de um meio educativo total, quer dizer, um meio no qual pudessem ser controladas todas as repercussões/incidências educativas (TRILLA, 1997).

Embora não se possa considerar a cidade educadora como proposta (no sentido literal do termo) de construção de política pública em Educação, compartilha-se, aqui, desta "ideia-força", uma vez que ela caminha na direção da horizontalização das relações entre Estado e sociedade civil. Talvez, desse modo, se possa, “[...] - en lugar de estrategias burocráticas, verticales o racionales del cambio - favorecer la emergencia de dinámicas autónomas de cambio, que puedan devolver el protagonismo a los agentes [...]" (BOLÍVAR, 2005, p. 864).

Em trabalho teórico-investigativo que teve como hipótese inicial as possibilidades democráticas de construção/reconstrução do Sistema Municipal de Ensino, de Ijuí (RS), Severino Verza diz que faz sentido repensar tal sistema em horizontes democráticos, convocando os cidadãos a exercerem seus direitos de construir/reconstruir as políticas sociais que dizem respeito às necessidades fundamentais de sua existência (VERZA, 2000).

$\mathrm{O}$ autor incorpora a ação participativa democrática como princípio orientador, e adota a postura epistemológica de Habermas, de superação da filosofia da consciência pela racionalidade comunicativa, entendendo que, com isso, novos caminhos se abrem à pesquisa participante.

O estar e participar, no caso dos agentes/técnicos e educadores, e no caso dos agentes do poder público municipal [...] e outros especialistas, têm como horizonte orientador e objetivo fazer nascer a discussão e o desenvolvimento de políticas públicas democráticas com a participação efetiva dos diferentes grupos e setores [...] em que se organizam os munícipes. Visa, outrossim, mediante debate público/democrático, detectar 
em maior profundidade as necessidades, os interesses, as expectativas e aspirações que movem os diferentes grupos e setores quanto à temática que se pretende enfrentar e estabelecer os caminhos viáveis à superação. [...] Necessitam, os diferentes grupos, setores, instituições, associações perceber que os técnicos/educadores, os especialistas, os agentes do poder público municipal estão realmente comprometidos com as mudanças a serem implementadas. Devem perceber que o próprio trabalho de propor, assessorar, ajudar, querer ouvir, escutar reconstruir propostas coletivas e democráticas é uma forma de compromisso e solidariedade social e política, com vistas a uma vida mais justa e digna. Aliás, os sujeitos populares têm fina sensibilidade para perceber até que ponto, principalmente agentes externos a seu meio, são sinceros e verdadeiros em seus intentos (VERZA, 2000, p. 251-252, grifos nossos).

Neste texto aflora a perspectiva de que, para a consecução do objetivo proposto, são necessários "agentes externos". Entende-se que há, nesta perspectiva, um privilegiamento do pesquisador como o portador do progresso. Há uma epistemologia que define o conhecimento do pesquisador como produtor de progresso (POPKEWITZ, 1997). É inevitável perceber, em sua proposta, uma concepção na qual os intelectuais seriam imprescindíveis para conduzir/liderar os cidadãos para a construção de políticas sociais democráticas.

É possível também se discutir a ideia de que o diálogo, a comunicação, a razão comunicativa abririam outras possibilidades, pois o "poder" argumentativo, o repertório que municia as argumentações, é um repertório desigual. Apostar no diálogo à exaustão, nas virtualidades da razão comunicativa, para chegar a consensos mínimos, é, de alguma forma, desconhecer o lugar do saber - e, portanto do poder argumentativo - que ocupam os diferentes envolvidos.

Além da proposta teórico/empírica analisada acima, é importante que se possa, também, conhecer experiências alternativas - no campo das políticas públicas em educação - que tenham sido efetivamente implementadas.

A partir da década de 1980, com o início da redemocratização do Brasil, começaram a ser implementadas novas políticas em educação, com o intuito de reorganizar a escola. Segundo Álvaro Chiarello, tais processos se deram,

principalmente nas capitais, dentre as quais destacamos a "Escola Plural", em Belo Horizonte, a "Escola Cidadã", em Porto Alegre e a "Escola Candanga", no Distrito Federal. O debate que se abriu sobre tais propostas, entre os docentes, evidenciou a existência de diferentes diretrizes políticas e pedagógicas, muitas vezes contraditórias entre si. Mostrou também grandes lacunas na fundamentação de seus princípios políticos e filosóficos, o que 
tornava difícil identificar, dentre outros aspectos, o tipo de projeto social e político para o qual aquelas propostas pretendiam educar: Qual o papel da instituição escolar no processo de transformação da sociedade? Qual o lugar da cultura e das ideologias nessas mudanças? Quais as estratégias de lutas mais adequadas para o efetivo alcance dos seus objetivos? (CHIARELLO, 2001, p. 1).

Assim, apresentam-se a seguir, três experiências desenvolvidas por administrações de Secretarias Municipais de Educação, que se pautaram pela perspectiva da democracia participativa, e uma experiência desenvolvida pela Divisão de Jovens e Adultos de uma Secretaria de Estado.

A primeira delas refere-se ao período em que a Administração pública da cidade de São Paulo contou com Paulo Freire como Secretário Municipal de Educação. Reflexões acerca da instituição escolar e críticas à escola burocrática são tópicos recorrentes que atravessam a obra de Paulo Freire, mesmo quando sua atenção incide sobre a educação comunitária e não escolar, e sobre dispositivos organizacionais alternativos, como os centros e os círculos de cultura, por exemplo. Freire defendeu sempre uma democracia participativa, necessariamente, social e cultural, que supõe a existência de estruturas democratizantes e possibilitadoras da participação da sociedade civil no comando da res-pública (LIMA, 2000).

Analisando o pensamento de Freire acerca dessa questão, Lima (2000) coloca que, em uma perspectiva freireana, a transformação da escola em "casa da comunidade" exige uma política de devolução democrática da escola à comunidade, através da descentralização e da autonomia, legitimadas por formas de governação democrática e de participação ativa na tomada de decisões. O que não significa a retirada do Estado, através da devolução de encargos, de medidas de desregulação e de privatização, abandonando a escola pública à sorte de um mercado educacional, que, muito dificilmente, terá interesse por intervenções junto aos setores populares.

Essas questões são tratadas em vários documentos da Secretaria Municipal de Educação de São Paulo, publicados durante o período em que Paulo Freire exerceu o cargo de Secretário. Em um texto produzido na administração de Freire, pode-se ler:

O que significa "participar" e "descentralizar" numa administração popular? Os mesmos objetivos estão presentes no discurso de políticos cuja orientação é oposta à nossa. O que nos diferencia deles é o conteúdo 
que imprimimos a esses princípios e a nossa decisão de não permitir que eles fiquem apenas no terreno das intenções [...] Para nós, descentralização e participação dizem respeito ao ato de decidir. $\mathrm{O}$ equívoco que mais frequentemente se comete em relação a essas questões é descentralizar a execução das tarefas e manter as decisões centralizadas (SME, 1992, p. 65-66).

Nesse sentido, uma das primeiras providências tomadas foi a reorganização política e administrativa da Secretaria. A democratização da gestão foi considerada um eixo norteador das políticas educacionais e não ficou reduzida à introdução de mudanças morfológicas nas escolas, mas implicou nova concepção de sua governação, necessariamente partilhada com a Secretaria, com as escolas e com seu entorno comunitário, partindo da premissa de que cabe ao cidadão decidir sobre aquilo que é público. Assim, a definição coletiva e participativa da política educativa da cidade exigia medidas concretas de democratização do poder educativo e pedagógico, objetivo esse que Freire considerou prioritário (LIMA, 2000).

Descentralização, administração por colegiados e participação nas decisões foram os princípios subjacentes à concepção de escola democrática, pública e popular que a gestão de Freire perseguiu. Nesse aspecto, a criação, em cada escola, de um conselho deliberativo (o Conselho de Escola), representou uma das mais relevantes mudanças introduzidas na governação escolar (LIMA, 2000). Ainda que a figura do conselho de escola não tenha sido criação da gestão de Freire, a "administração por colegiados" estendeu-se a todos os níveis da administração: em nível local, pela ação dos conselhos de escola; em nível regional, através dos colegiados intermediários; em nível central, através dos colegiados centrais (SME, 1992).

$\mathrm{Na}$ sequência da análise de experiências alternativas que tenham sido efetivamente implementadas, no campo das políticas públicas em educação, vale destacar, também, a experiência ocorrida durante os dez primeiros meses da segunda gestão (1993-1996) do Partido dos Trabalhadores, na Secretaria Municipal de Educação de Porto Alegre. A opção política dessa gestão pretendia estabelecer uma nova relação de poder assentada no trinômio participação, descentralização e autonomia (POOLI, 1999).

Nesse período, a criação dos Conselhos Escolares tentou resgatar a democratização do sistema. Com poder deliberativo, administrativo e pedagógico, essas organizações teriam um perfil democrático e autônomo, com seus integrantes sendo escolhidos através de eleições diretas, com peso idêntico para toda a comunidade escolar. Além disso, neste período estava sendo rees- 
truturada a Assessoria Comunitária, que era responsável pela articulação das relações da Secretaria com a comunidade, criando canais de participação para pais, professores, alunos e funcionários das escolas, assim como para usuários de equipamentos públicos (POOLI, 1999).

"As propostas de trabalho enfatizaram a democratização do sistema de ensino, rompendo com uma tradição administrativa de propor diálogo com a comunidade somente para escutar seus próprios apelos" (POOLI, 1999, p. 195). Na avaliação do autor, a educação democrática foi o eixo transversal de toda a gestão, fazendo parte de uma ideia mais ampla da própria administração municipal.

Nas gestões subsequentes do Partido dos Trabalhadores à frente da Prefeitura de Porto Alegre (1994-1996; 1997-2000; 2001-2004), a SMED criou e consolidou a "Escola Cidadã", na qual foi implementada uma reestruturação curricular, e da qual se teve a oportunidade de participar, como membro da equipe de Assessoria Pedagógica da Secretaria Municipal de Educação.

Ao abordar a questão da investigação na área das políticas educacionais, Vitor Henrique Paro afirma:

$\mathrm{Na}$ condição de intelectual comprometido com a transformação social, o analista e idealizador de políticas educacionais tem o dever e a responsabilidade de contribuir com elementos teóricos que, integrados numa nova concepção de mundo, voltada para a transformação, concorram para a desejada "reforma intelectual e moral". Isso não pode acontecer sem a busca intencional da ligação entre a teoria e a prática e sem que a atividade teórica desenvolvida na academia se acerque da concretude da escola (PARO, 2001, p. 46).

Para efetivar a reestruturação, foi iniciado o processo denominado de Constituinte Escolar (AZEVEDO, 1999; FREITAS, 1999; LOCH, 1999; KRUG, 2001). O primeiro movimento desencadeador deste processo foi a discussão, por parte da comunidade escolar (ali entendida como constituída de quatro segmentos, a saber: pais, alunos, professores e funcionários), sobre a "escola que temos" e a "escola que queremos". O objetivo de tais discussões foi conhecer quais eram, na perspectiva da comunidade escolar, os mais sérios entraves e quais eram os desejos, aspirações da mesma com relação à escola.

A partir daí, as discussões passaram a girar em torno de quatro eixos: a democratização da gestão da escola; princípios de convivência; concepção de currículo e conhecimento; avaliação. As pessoas envolvidas escolhiam a temática por interesse e/ou afinidade. Ou seja, a escolha não foi direcionada. Os grupos 
de discussão foram, desta forma, constituídos por membros dos diferentes segmentos, o que permitiu uma pluralidade de olhares acerca da temática em pauta. Os grupos eram coordenados por assessores da Secretaria Municipal de Educação (SMED), que fomentavam e subsidiavam as discussões com textos e dinâmicas, objetivando questionar as visões e práticas instituídas, e estabelecer princípios norteadores para a construção da "escola que queremos".

Cada escola socializava e debatia os princípios construídos e elegia os seus delegados para um encontro com as demais escolas de sua região. Nestes encontros regionais, fizeram-se novas tomadas de discussão, se estabeleceram/ ampliaram princípios acerca das quatro temáticas e se elegeram representantes regionais. Estes participaram da elaboração da "Constituinte Escolar", conjunto de princípios que nortearam os novos regimentos escolares em toda Rede Municipal de Ensino. Tendo a "Constituinte Escolar" como balizador, a Secretaria formulou uma proposta de reestruturação curricular e apresentou-a às escolas, que poderiam, ou não, aderir a ela. A experiência da Escola Cidadã passou por modificações constantes, mas se manteve, enquanto proposta políticopedagógica, até 2004, quando outro partido político assumiu a Administração Municipal.

Outra experiência alternativa envolvendo políticas públicas em educação ocorreu durante a gestão de Cristovan Buarque (1997-2000), quando foi criada, em Brasília, a Escola Candanga. Esta era um projeto político-pedagógico de cunho popular, que procurava não limitar seu foco a indicadores e metas quantitativas. Este projeto ofereceu oportunidades para a participação efetiva das famílias na escola, inclusive, oferecendo educação para pais e mães de baixa renda, procurando, dessa forma, estimular o desenvolvimento da comunidade como um todo.

O currículo da Escola Candanga estruturava-se em três dimensões (ALCOBA, 2003): a) dimensão filosófica: defendia o exercício da razão crítica. Amparava-se no princípio da reflexão, visando compreender a realidade aparente, como esta foi produzida histórica e socialmente, e quem seriam os agentes sociais que a transformariam; b) dimensão sócio-antropológica: buscava a interação entre educação, cultura e tecnologia. Pautava-se por uma perspectiva integradora, que procurava romper com a fragmentação do conhecimento e construir um ser humano ativo, com pensamento vinculado a um ambiente histórico e social. Pretendia redescobrir o sentido da ação coletiva, o sentimento de pertencer a um grupo social e o significado da participação no processo de formação de identidade cultural; c) dimensão psicopedagógica: tinha como eixos norteadores a ética e a ecologia. Pretendia questionar a situação políticosocial vigente, criticando a sociedade cujo fim é o lucro, questionando, assim, as formas de poder. 
A Escola Candanga, mesmo sendo criticada pela adoção dos ciclos de formação - que, na visão de José Carlos Azevedo, ex-reitor da Universidade de Brasília (UnB), serviriam "apenas para ocultar a evasão e a repetência” (ISTO É, 1997), foi reconhecida, até mesmo, pelo Banco Mundial - por reduzir os custos do Estado com a repetência (HORN, 2002). O projeto Escola Candanga foi suspenso em 2001, quando um partido de oposição assumiu o governo.

Outra experiência que caminha na direção contrária à da tradição brasileira está sendo implementada pela Secretaria Estadual de Educação do Rio Grande do Sul, no âmbito da Educação de Jovens e Adultos. Em documento intitulado "Diretrizes político-pedagógicas - Ressignificando a Educação de Jovens e Adultos" - são apresentadas as diretrizes desta modalidade de ensino para o período 2003-2006.

O documento explicita que a perspectiva da Educação de Jovens e Adultos (EJA), é a de comprometer-se com a inclusão educacional - inclusão esta que construa possibilidades de intervenção cidadã - encaminhando para a inclusão social, partindo da leitura de mundo para chegar à leitura da palavra.

As referidas diretrizes partem da concepção de que, ao Estado, cabe definir

políticas públicas que assegurem as questões educacionais dessa modalidade por meio de parcerias com os Municípios, com a Sociedade Civil, com as Instituições de Ensino Superior, com as ONGs [...] (DEJA - SE/RS, 2004, p. 4, grifo nosso).

Além disso, no documento pode-se ler que:

É fundamental uma cultura educacional que seja pautada nas condições de acesso, de progressão, de superação, cabendo aos gestores públicos, aos professores e à sociedade civil investir nessas instâncias, reafirmando identidades. Acredita-se que uma política educacional, se comprometida, pode (re)criar e preparar os espaços educativos e os seus atores (DEJASE/RS, 2004, p. 6).

Dentre os princípios que norteiam as ações da Divisão de Educação de Jovens e Adultos (DEJA) da Secretaria de Educação, encontram-se, entre outros, a descentralização das ações, a parceria com segmentos governamentais e não 
governamentais e a mobilização da comunidade educacional e da sociedade. Como forma de se alcançar tais princípios, foram estabelecidas metas, dentre as quais se encontram, entre outras, o estabelecimento de convênios entre o Estado e as Instituições de Ensino Superior, Municípios, Entidades governamentais e não governamentais e sociedade civil, visando com isso descentralizar as propostas pedagógicas e metodológicas. O documento enfatiza que "Acredita-se que a multiplicidade de propostas teóricas e metodológicas enriquece a diversidade na formação" (DEJA - SE/RS, 2004, p. 22).

Também na perspectiva da descentralização, pode-se ler no documento que

Defende-se uma proposta político pedagógica descentralizada que deve ser assegurada através do Grupo de Trabalho de Educação de Jovens e Adultos (GTEJAs) [...] (DEJA - SE/RS, 2004, p. 21, grifo nosso).

O GTEJA é constituído pelo responsável da EJA na Coordenadoria Regional de Educação (CRE); por um representante de cada Secretaria Municipal de Educação da região; por um representante de cada Instituição de Ensino Superior que atua na região; por representantes de cada entidade conveniada; por um representante de segmentos ligados à execução do trabalho.

As atribuições dos GTEJAs envolvem: mobilização das comunidades regionais e locais; avaliação da necessidade de implantação, organização e avaliação de turmas de alfabetização; sugestões sobre a implantação e ampliação da rede pública escolar; definição de metas de alfabetização e de continuidade de estudos; avaliação do trabalho realizado pelas entidades parceiras, visando à renovação (ou não) dos convênios; proposição e orientação sobre as ações de qualificação e formação de recursos humanos (que serão executadas pelas Instituições de Ensino Superior); monitoramento das atividades programadas e avaliação de resultados alcançados.

Nas considerações finais do documento, é expressa a concepção de que a Educação de Jovens e Adultos ocorre na construção de possibilidades.

Tanto a experiência da Secretaria Municipal de Educação de São Paulo, quanto as experiências da Secretaria Municipal de Educação de Porto Alegre e da Escola Candanga, de Brasília, assim como a política de EJA do Rio Grande do Sul, apresentam formas de se entender e de se fazer política educacional que expressam uma concepção de homem, de mundo e de sociedade, que procuram caminhar na direção da horizontalização das relações entre Estado e sociedade 
civil (MORAES, 2004a; 2004b). Percebe-se, nessas experiências, não apenas a tentativa de rompimento com a ideia de intelectuais "iluminados", agindo como vanguarda, mas, fundamentalmente, percebe-se a valorização da participação da comunidade, a busca da co-governação, a tentativa de fazer com que a ação do Estado seja menos regulatória e mais emancipatória. Dentro deste contexto, o termo "governação" é utilizado, aqui, no mesmo sentido compreendido por Licínio Lima:

Do latim gubernatione, a palavra "governação" (já usada em língua portuguesa pelo menos desde o século XV) significa condução, direcção, acção ou efeito de governar. Embora seja apresentada [...] como sinónimo de administração e de governo, entendo destacar a ideia de processo, exercício e acção de governar, mais do que os sentidos de instituição ou de aparelho político-administrativo, ou ainda de estruturas, órgãos e poderes formais de governo (LIMA, 2000, p. 19).

A natureza de uma política educacional alternativa, com pressupostos de governação/co-governação, não pode ser pensada doutrinariamente, mas no próprio processo sociopolítico administrativo. A realidade social contemporânea nos mostra que as políticas de educação não são uníssonas, que há caminhos diferenciados de fazê-las. Mostra-nos também que elas podem contar com o ímpeto de uma democracia ascendente, que não quer somente um Estado ético e transparente, mas quer participar dele de modo mais próximo e intenso (CURY, 2002). Assim, a transformação do Estado passa, necessariamente, pela transformação da sociedade e o grande desafio da Educação é de "reconstruir um novo senso comum capaz de dar suporte quotidiano a uma pedagogia da esperança no futuro da humanidade, valorizando a acção política enquanto espaço e tempo de possibilidade" (TEODORO, 2003, p. 11).

Ainda que sejam levados em conta os recuos e obstáculos, as dificuldades e entraves que caracterizam as mudanças de paradigmas em políticas públicas educacionais, é de se ressaltar que, nos últimos anos, têm-se construído, em Belém (Escola Balaia), em Belo Horizonte (Escola Plural), em Blumenau (Escola Sem Fronteiras), em Brasília (Escola Candanga), em São Paulo, em Porto Alegre (Escola Cidadã) e em outras cidades do país, novas formas de fazer política pública em educação. Estas procuram derrubar os muros que separam Estado e sociedade civil e, de alguma forma, caminhar na direção da co-governação. As administrações que têm empreendido tais esforços caracterizam-se por pertencer a governos que consideram essenciais a participação da coletividade na decisão/ 
implementação de políticas públicas em educação. Tais experiências no campo da educação refletem projetos de governo que trazem consigo a concepção de democratização das relações entre Estado e sociedade, e podem representar novas esperanças de solução para velhos problemas.

\section{REFERÊNCIAS}

ALCOBA, S. A. C. Experiências de transformação de sistemas educacionais. Seminário Escolas Abertas à Diversidade. Campinas, jun. 2003. Disponível em: <http://www. alcoba.com.br/seminarios.html >. Acesso em: 14/06/2004.

ASOCIACIÓN Internacional de Ciudades Educadoras (AICE). Folleto introductorio. Disponível em: <http://www.ben.es/edcities/aice/adjunts/ciudad-educadora-Es.pdf>. Acesso em: 21/02/2004.

AZEVEDO, J. C. de. Escola cidadã: construção coletiva e participação popular. In: SILVA, L. H. da (Org.). Escola Cidadã no contexto da globalização. 3. ed. Petrópolis: Vozes, 1999. p. 308-319.

. Escola cidadã: desafios, diálogos e travessias. Petrópolis: Vozes, 2000.

BOLÍVAR, A. ¿Donde situar los esfuerzos de mejora?: Política educativa, escuela y aula. Educação \& Sociedade, Campinas, v. 26, n. 92, p. 859-888, out. 2005.

CABALLO VILLAR, M. B. A cidade educadora: nova perspectiva de organização e intervenção municipal. Lisboa: Instituto Piaget, 2001.

CARBONEL, J. S. Escola e entorno. In: AZEVEDO, J. C. et al. (Org.). Utopia e Democracia na Educação Cidadã. Porto Alegre: Editora da Universidade, 2000. p. 291-309.

CHIARELlO, Á. B. O desenvolvimento da escola na perspectiva gramsciana. 19 nov. 2001. Disponível em: <http://www.educabrasil.com.br/eb/exe/secao. asp?ps $=5 \&$ secao $=1 \&$ Cat $=1>$. Acesso em: 18/11/2003.

CURY, C. R. J. Políticas de educação: um convite ao tema. In: FÁVERO, O.; SEMERARO, G. (Org.). Democracia e construção do público no pensamento educacional brasileiro. Petrópolis: Vozes, 2002. p. 147-162. 
DIVISÃO de Educação de Jovens e Adultos (DEJA), Secretaria Estadual de Educação do Rio Grande do Sul. Diretrizes político-pedagógicas: ressignificando a Educação de Jovens e Adultos (SE/RS), 2003/2006. Porto Alegre: Secretaria de Educação do Rio Grande do Sul, 2004.

FREITAS, A. L. S. Projeto constituinte escolar: a vivência da "reinvenção da escola" na Rede Municipal de Porto Alegre. In: SILVA, L. H. da (Org.). Escola Cidadã: teoria e prática. Petrópolis: Vozes, 1999. p. 31-45.

HORN, R. Brazil: equitable, competitive, sustainable - contributions for debate. In: World Bank, Part 1, 2002. p. 105-154.

ISTO É. A vida em ciclos. São Paulo, n. 1463, 15 out. 1997.

KRUG, A. Ciclos de formação: uma proposta político-pedagógica transformadora. Porto Alegre: Mediação, 2001.

LIMA, L. Organização escolar e democracia radical: Paulo Freire e a governação democrática da escola pública. São Paulo: Cortez, 2000.

LOCH, J. M. P. Avaliação na escola cidadã. In: ESTEBAN, M. T. (Org.). Avaliação: uma prática em busca de novos sentidos. Rio de Janeiro: DP\&A, 1999. p. 129-142.

MORAES, S. C. de. Novas Ágoras: desenhos alternativos para uma política em educação. Tese (Doutorado em Educação) - Programa de Pós-graduação em Educação, Universidade do Vale do Rio dos Sinos, São Leopoldo, 2004a.

. É possível a construção de políticas públicas emancipatórias em educação? Revista Portuguesa de Educação, Lisboa, v. 17, n. 2, p. 225-246, 2004 b.

PARO, V. H. Políticas educacionais: considerações sobre o discurso genérico e a abstração da realidade. In: DOURADO, L. F.; PARO, V. H. (Org.). Políticas Públicas \& Educação Básica. São Paulo: Xamã, 2001. p. 29-47.

POOLI, João Paulo. Educação, Estado e Políticas Públicas: gestão democrática para a educação. Tese (Doutorado em Educação) - Faculdade de Educação, UFRGS, Porto Alegre, 1999.

POPKEWITZ, T. S. Reforma educacional: uma política sociológica - poder e conhecimento em educação. Porto Alegre: Artes Médicas, 1997.

SECRETARIA MUNICPAL DE EDUCAÇÃO. Planejamento: instrumento de mobilização popular. São Paulo: Prefeitura Municipal de São Paulo, 1992.

SOUSA SANTOS, B. de. Seis razões para pensar. Lua Nova Revista de Cultura e Política, São Paulo, n. 54, p. 13-23, 2001. 
. Para uma sociologia das ausências e uma sociologia das emergências. In: . (Org.). Conhecimento prudente para uma vida decente. Porto: Afrontamento, 2003. p. 735-775.

TEODORO, A. É possível uma política de educação à esquerda? Uma reflexão sobre possibilidade e esperança na acção política. Revista Lusófona de Educação, Lisboa, n. 2, p. 43-51, 2003.

. Globalização e Educação. Políticas educacionais e novos modos de governação. São Paulo: Cortez, 2004.

. Mandato e legitimação nas políticas para a educação. Entrevistadora: Olinda Evangelista. Perspectiva, Florianópolis, v. 23, n. 01, p. 223-234, jan./jul. 2005.

TRILLA, J. B. Ciudades Educadoras: bases conceptuales. In: ZAINKO, M. A. S. (Org.). Cidades Educadoras. Curitiba: Ed. da UFPR, 1997. p. 13-34.

VERZA, S. B. As políticas públicas de educação no município. Ijuí: UNIJUí, 2000.

Texto recebido em 30 de março de 2006. Texto aprovado em 12 de março de 2009. 